\title{
PROSES PELAPISAN BAJA DENGAN METODE SEMBURAN KAWAT LAS OKSI-ASITILEN
}

\author{
Muhammad Ridlwan \\ Jurusan Teknik Mesin Fakultas Teknologi Industri \\ Universitas Islam Indonesia, Yogyakarta \\ Email : ridlwanm@fti.uii.ac.id
}

\begin{abstract}
Wire flame spray process is one of metal coating technique. The flame spray process is basically the spraying of molten metal onto a surface to provide a coating. Material in wire form is melted in a flame (oxy-acetylene flame most common) and atomized using compressed air to form a fine spray. When the spray contacts the prepared surface of a substrate material, the fine molten droplets rapidly solidify forming a coating.

In this research, commercial steel wire (Fe-C), which has $1.25 \mathrm{~mm}$ in diameter, was used as raw material. The wire was heated and melted by two oxy-acetylene nozzles and then sprayed onto steel bar surface to form a coating. Vickers hardness testing and optical microscope were used to define the coating characteristic.

The result shows that the coating has higher hardness number than the substrate material and the intrusion of carbon was founded in the coating microstucture.

Keywords: coating process, wire flame spray, oxy-acetylene
\end{abstract}

\section{PENDAHULUAN}

Jumlah kerugian akibat korosi di Indonesia, secara kuantitatif belum pernah dilakukan, namun sebagai gambaran kerugian akibat serangan korosi di Amerika dapat mencapai sekitar 24 triliun rupiah pertahun. Jumlah ini belum mencakup kehilangan jam produksi, ganti rugi kerusakan, klaim-klaim, biaya perbaikan dan lain-lain. Proses pelapisan diperlukan untuk melindungi produk-produk logam dari serangan korosi, apalagi bagi negara-negara yang memiliki iklim tropis seperti Indonesia.

Proses pelapisan diperlukan juga untuk memperbaiki produk-produk logam terutama baja yang telah mengalami keausan. Sebagai contoh rel kereta api mengalami keausan akibat bergesekan dengan roda kereta api pada saat melakukan pengereman. Untuk langsung mengganti rel tersebut dengan rel yang baru tentu saja hal tersebut tidak efisien, maka diperlukan proses pelapisan atau penambahan logam yang dapat melekat kuat dengan rel kereta yang aus tersebut.

Berdasarkan alasan di atas maka diperlukan penelitian mengenai proses pelapisan logam terutama baja yang mampu melindungi produk dari serangan korosi dan memperbaiki produk yang telah mengalami keausan. 


\section{TUJUAN PENELITIAN}

Tujuan penelitian ini adalah melakukan proses pelapisan logam dengan metoda semburan kawat las oksi-asitilen serta meneliti karakteristik lapisan yang dihasilkan dari proses tersebut.

\section{TINJAUAN PUSTAKA}

Proses semburan logam panas (metal flame spray process) adalah salah satu teknik pelapisan logam (coating) yaitu dengan cara menyemburkan logam cair ke permukaan benda kerja yang akan dilapisi. Beberapa teknologi yang digunakan dalam proses semburan panas, yaitu : nyala oksi-asitilen, busur listrik, dan busur plasma. Bentuk material awal dari logam pelapis dapat berupa kawat (wire) atau serbuk (powder). Jika bentuk material awal berupa kawat, maka proses ini sering disebut dengan proses semburan kawat atau wire spray. [1]

Partikel logam cair yang disemprotkan dari nosel mempunyai ukuran diameter 0,0001 - 0,00015 inchi pada jarak penyemprotan optimum yaitu antara 4 10 inchi. Semburan ini kemudian menabrak permukaan benda kerja sehingga terjadi ikatan antara logam cair dengan permukaan benda kerja, membentuk lapisan logam. [2]

Proses semburan kawat oksi-asitilen (oksi-asitylene wire spray) adalah proses pelapisan logam dengan semburan panas dengan sumber energi nyala oksi-asitilen dan bentuk material awal logam pelapis berupa kawat.

\subsection{Proses Semburan Kawat Oksi-Asitilen}

Proses semburan panas kawat oksi-asitilen adalah salah satu teknik pelapisan logam (coating) dengan cara menyemburkan logam cair ke permukaan benda kerja yang akan dilapisi. Prinsip kerja dari proses ini dapat dilihat pada Gambar 1, yaitu : Material pelapis yang berbentuk kawat dilewatkan ke dalam nyala oksi-asitilen, yang mempunyai temperatur kurang lebih $3480^{\circ} \mathrm{C}$, dipanaskan hingga mencair. Peralatan semburan kawat oksi-asitilen dapat dilihat pada Gambar 2.

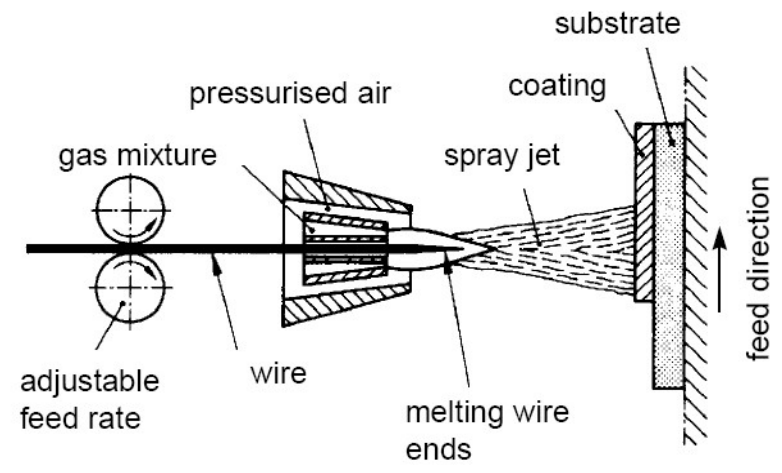

Gambar 1. Skema Proses Semburan Panas Kawat Oksi-Asitilen. [3] 


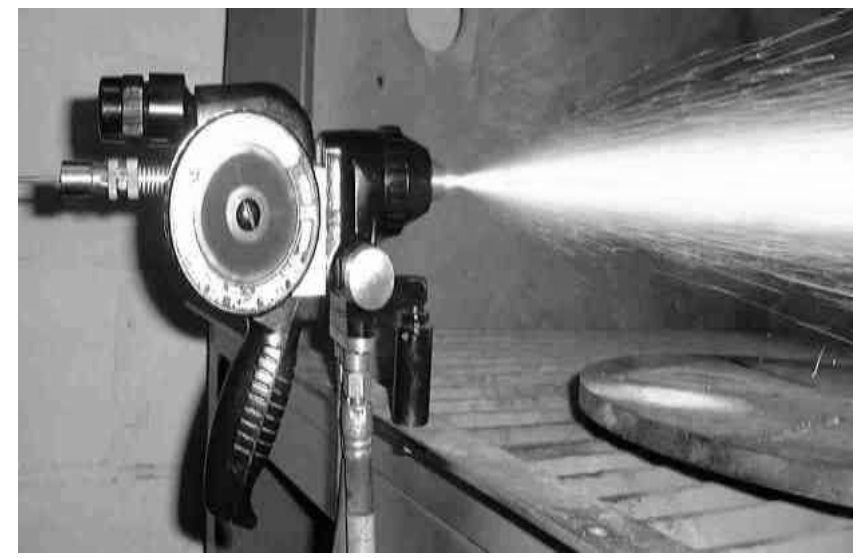

Gambar 2. Nosel pada Proses Semburan Panas Kawat Oksi-Asitilen. [3]

\subsection{Las Oksi-Asitilen}

Pengelasan dengan gas dilakukan dengan membakar bahan bakar gas dengan $\mathrm{O} 2$ sehingga menimbulkan nyala api dengan suhu yang dapat mencairkan logam induk dan logam pengisi. Sebagai bahan bakar dapat digunakan gas-gas asitilen, propan atau hidrogen. Dari ketiga bahan bakar ini gas asitilen paling banyak digunakan. [4]

Dalam nyala oksi-asitilen netral terjadi dua reaksi bertingkat yaitu :

Pada kerucut dalam:

$$
\mathrm{C} 2 \mathrm{H} 2+\mathrm{O} 2 \quad 2 \mathrm{CO}+\mathrm{H} 2
$$

Pada kerucut luar:

$$
\begin{array}{ll}
2 \mathrm{CO}+\mathrm{O} 2 & 2 \mathrm{CO} 2 \\
2 \mathrm{H} 2+\mathrm{O} 2 & 2 \mathrm{H} 2 \mathrm{O}
\end{array}
$$

Distribusi temperatur nyala oksi-asitilen netral dapat dilihat pada Gambar 3 berikut :

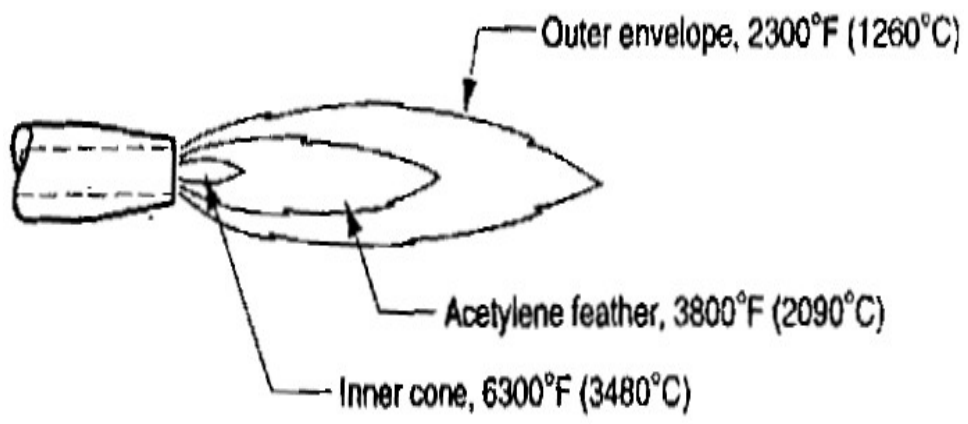

Gambar 3. Distribusi temperatur nyala oksi-asitilen netral. [5] 


\section{METODE PENELITIAN}

\subsection{Bahan dan Peralatan Penelitian}

Logam yang dilapisi adalah baja ST 37 yang berbentuk plat dengan panjang $36 \mathrm{~mm}$ dan lebar $25 \mathrm{~mm}$. Material awal logam pelapis adalah kawat baja komersial dengan diameter $1.25 \mathrm{~mm}$.

Proses pelapisan dilakukan dengan menggunakan dua buah torch las dan berjarak $75 \mathrm{~mm}$ dengan logam dasar. Peralatan semburan kawat oksi-asitilen yang digunakan dalam penelitian ini seperti pada gambar 4 berikut :

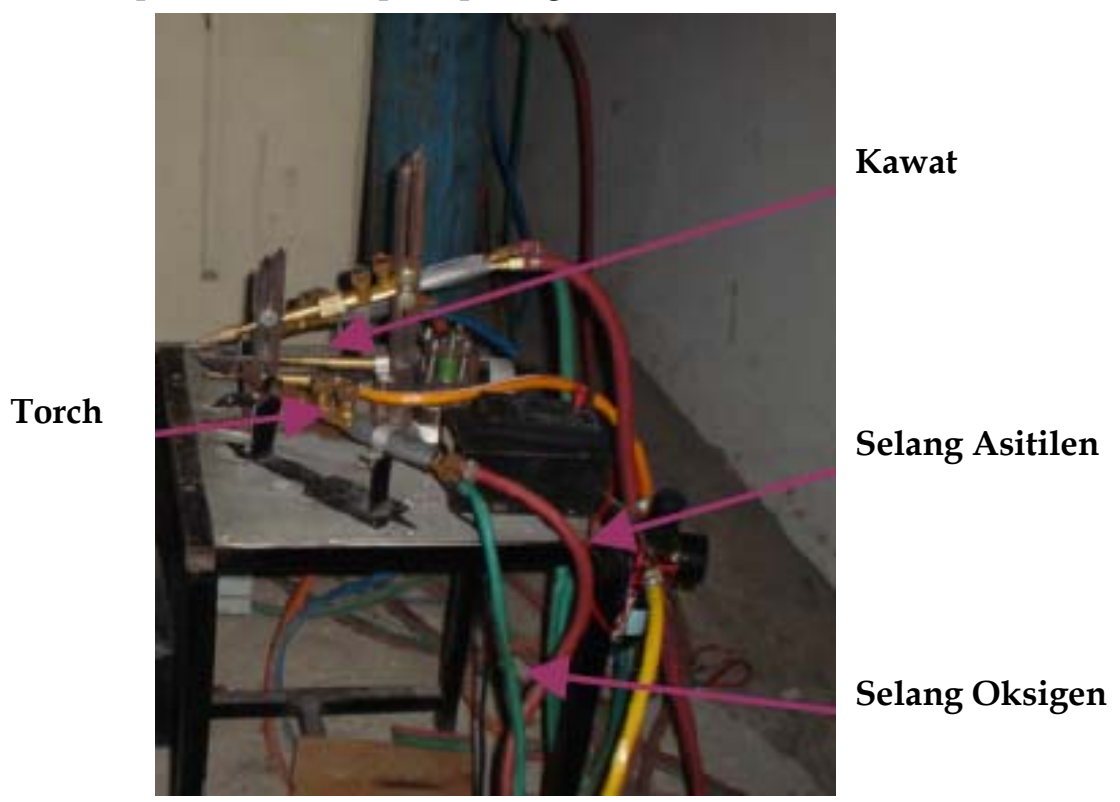

Gambar 4. Peralatan semburan kawat oksi-asitilen

\subsection{Pengujian Karakteristik Lapisan}

\subsubsection{Pengujian Kekerasan}

Pada pengujian kekerasan ini menggunakan pengujian Vickers dengan penetrator piramida intan $136^{\circ}$. Pengujian kekerasan dilakukan pada logam induk dan lapisan yang dihasilkan dari proses semburan kawar. Angka kekerasan Vickers kemudian ditentukan dengan rumus berikut :

$$
\mathrm{VHN}=\frac{2 F \sin \frac{\theta}{2}}{d^{2}}=1,8544 \frac{F}{d^{2}}
$$

Dimana: $\quad$ F : beban yang dipergunakan (kgf)

$\mathrm{d}$ : panjang diagonal rata-rata $(\mu \mathrm{m})$

$\theta$ : sudut antara permukaan intan yang berlawanan $=136^{\circ}$ 


\subsubsection{Pengujian Struktur Mikro}

Pengujian struktur mikro ini bertujuan untuk mengetahui struktur mikro logam induk dan lapisan. Pengamatan struktur mikro dilakukan dengan menggunakan mikrosokop optik dengan perbesaran 100X.

\section{HASIL DAN PEMBAHASAN}

\subsection{Pengujian Kekerasan Lapisan}

Pengujian kekerasan dilakukan dengan Vickers Mikro Hardness pada logam dasar, daerah lapisan, daerah transisi, masing-masing sebanyak dua kali. Hasil pengujian kekerasan ditabelkan pada Tabel 1 berikut :

Tabel 1. Hasil Pengujian Kekerasan Vickers

\begin{tabular}{|l|c|c|c|}
\hline \multicolumn{1}{|c|}{ Daerah } & Pengujian 1 & Pengujian 2 & Rata-rata \\
\hline Logam Dasar & 124 & 123 & 123.5 \\
\hline Butir Lapisan & 157 & 156 & 156.5 \\
\hline Lapisan & 525 & 450 & 487.5 \\
\hline
\end{tabular}

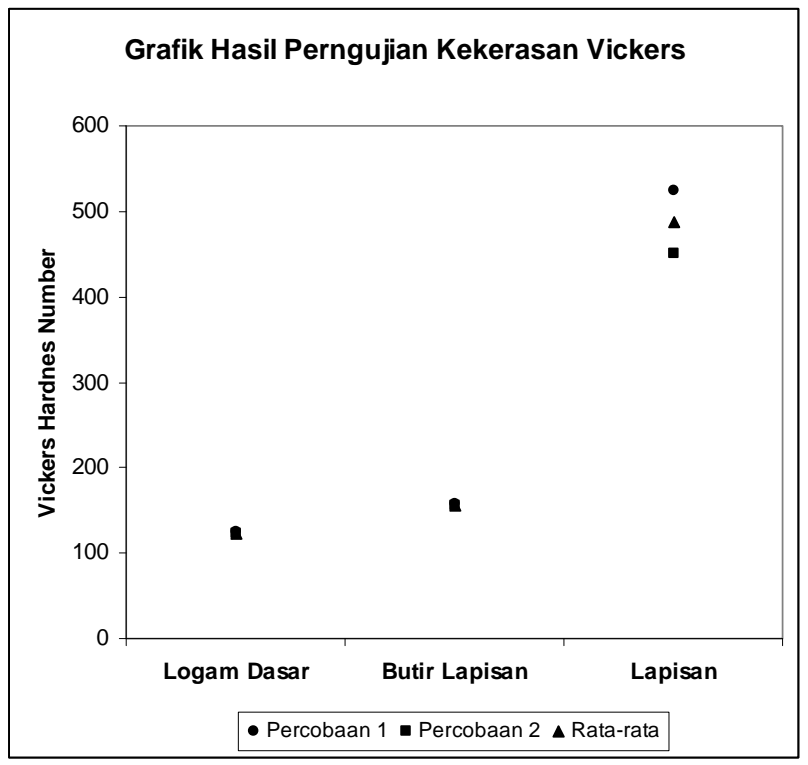

Gambar 5. Grafik Hasil Pengujian Kekerasan Vickers

Hasil pengujian kekerasan tersebut kemudian dibuat grafik seperti pada Gambar 5. Berdasarkan hasil tersebut terlihat bahwa daerah lapisan memiliki kekerasan yang lebih tinggi daripada logam dasarnya. Pada daerah lapisan 
mengalami penambahan karbon yang berasal dari nyala oksi-asitelen sehingga dapat meningkatkan kekerasan dari logam lapisan. Logam lapisan sebelum menempel pada logam dasar berbentuk cair. Pada saat disemburkan, logam cair tersebut mengalami pendinginan yang cepat. Hal tersebut dapat juga menyebabkan kekerasannya meningkat.

\subsection{Pengujian Struktur Mikro}

Berikut adalah gambar hasil pengamatan struktur mikro hasil proses semburan kawat oksi-asitilen :

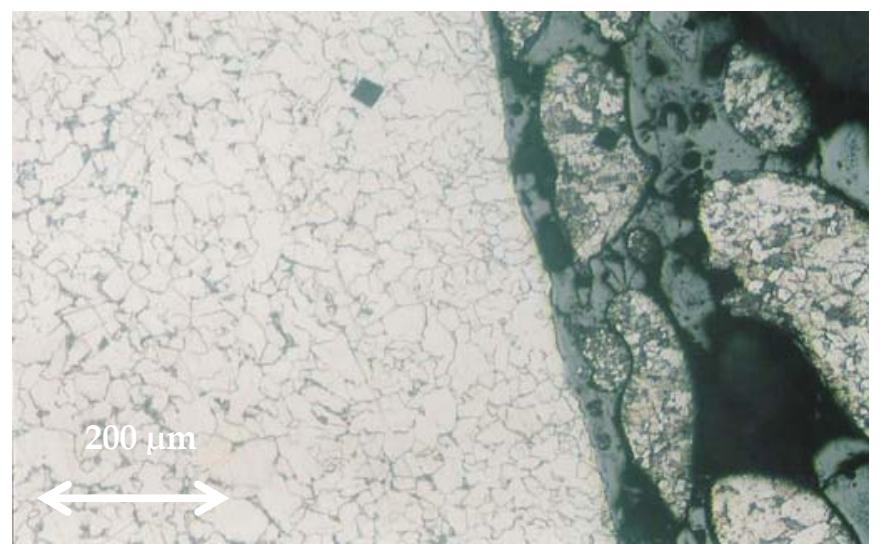

Gambar 6. Struktur mikro hasil proses semburan kawat oksi-asitilen

Pada gambar 6 terlihat struktur mikro dari logam dasar, ditunjukkan oleh warna putih sebelah kiri. Pada bagian sebelah kanan terlihat struktur mikro dari daerah lapisan. Pada daerah lapisan terlihat tiga macam warna, yaitu warna putih menunjukkan butir lapisan, warna kelabu menunjukkan lapisan, dan warna hitam menunjukkan adanya karbon yang menempel pada lapisan.

Lapisan berwarna kelabu dan memiliki kekerasan yang tinggi menunjukkan bahwa pada saat lapisan masih berbentuk cair terjadi reaksi antara lapisan dengan karbon, sehingga warna lapisan berubah menjadi kelabu. Butir lapisan berbentuk rounded menunjukkan bahwa sebagian logam cair telah mengalami pembekuan di udara sebelum menempel pada logam dasar.

\section{SIMPULAN}

Dari pengujian diatas dapat diambil kesimpulan yaitu proses pelapisan logam dengan metoda semburan kawat las oksi-asitilen dapat dilakukan pada material baja. Lapisan yang terbentuk dari proses tersebut memiliki nilai kekerasan vickers cukup tinggi yaitu 487 dan berwarna hitam disebabkan adanya karbon yang berasal dari nyala oksi-asitelen menempel pada lapisan. 


\section{DAFTAR PUSTAKA}

[1] Ridlwan, M., 2004, Proses Pembuatan Serbuk dengan Metoda Atomisasi Las OksiAsitilen, Penelitian Pasca Sarjana, Teknik Mesin UGM, Yogyakarta

[2] German, M.R., 1972, Powder Metallurgy Science, Metal Powder Industries Federation, Jakarta

[3] http://www.hvof.com/metalliz.htm

[4] Harsono, W., dan Okumura, T., 1996, Teknologi Pengelasan Logam, PT. Pradnya Paramita, Jakarta

[5] Groover, M.P., 1996, Fundamental of Modern Manufacturing, Prentice Hall, New Jersey 